\title{
A PRODUÇÃO HISTORIOGRÁFICA SOBRE AS INSTITUIÇÕES ESCOLARES AGRÍCOLAS NO BRASIL ${ }^{1}$
}

\section{HISTORICAL PRODUCTION EDUCATIONAL INSTITUTIONS ON THE AGRICULTURAL IN BRAZIL}

\author{
Vera Lucia Martiniak ${ }^{2}$ \\ José Luis Sanfelice ${ }^{3}$ \\ Maria Isabel Moura Nascimento ${ }^{4}$
}

\begin{abstract}
RESUMO
O objetivo do estudo é elaborar uma síntese interpretativa do conhecimento referente à produção acadêmica que aborda a temática instituição escolar. Para a análise da produção científica consideraram-se as pesquisas, dissertações e teses produzidas no período de 1998 a 2006. Procedeu-se ao levantamento dos trabalhos produzidos nos Programas de Pós-Graduação, procurando averiguar, conforme a temática selecionada, a possível reincidência do tema empregado nessas pesquisas. A análise empreendida concebeu a constituição da realidade inserida no processo histórico, a qual, por força da luta provocada pelas contradições, efetivou-se num processo dialético. O embasamento teórico que a orienta parte da afirmação de Karl Marx ao compreender o homem como sujeito real, pois vive numa realidade objetiva concreta, material, e tem sua historicidade.
\end{abstract}

Palavras-chave: Historiografia. Instituições escolares. Ensino agrícola.

\begin{abstract}
This study developed an interpretative synthesis of the knowledge produced about schools in academic research. The analysis included dissertations and theses produced from 1998 to 2006 in post-graduate programs. The study looked for the recurrence of the theme in such studies. The analysis demonstrates that reality is inserted in a historical dialectical process caused by contradictions. The theoretical
\end{abstract}

\footnotetext{
${ }^{1}$ Este artigo é parte da pesquisa de doutoramento e traz os resultados da análise do Estado do Conhecimento sobre as instituições escolares agrícolas no Brasil. ${ }^{2}$ Aluna do Programa de Pós-Graduação em Educação da Universidade Estadual de Campinas-UNICAMP/SP. Professora do Departamento de Métodos e Técnicas de Ensino da Universidade Estadual de Ponta Grossa e coordenadora do Curso de Licenciatura em Filosofia da Faculdade Santana. E-mail: vlmartiniak@uepg.br ${ }^{3}$ Professor da Pós-Graduação em Educação da Universidade Estadual de Campinas-UNICAMP/SP e orientador da pesquisa. E-mail: sanfelice00@hotmail.com ${ }^{4}$ Professora da Pós-Graduação da Universidade Estadual de Ponta Grossa-UEPG e coordenadora do grupo de pesquisa HISTEDBR Campos Gerais. E-mail: misabel@lexxa.com.br
} 
framework that supported the analysis was based on Karl Marx's understanding of man as a real subject that lives in an objective concrete, material reality that has its historicity.

Keywords: Historiography. Educational institutions. Agricultural education.

Neste texto busca-se elaborar uma síntese interpretativa do conhecimento referente à produção acadêmica que aborda a temática instituição escolar. Para o empreendimento da análise da produção científica consideraram-se as pesquisas, dissertações e teses produzidas no período de 1998 a 2006. A análise empreendida procedeu ao levantamento dos trabalhos produzidos nos Programas de Pós-Graduação, procurando averiguar, conforme a temática selecionada, a possível reincidência do tema empregado nessas pesquisas.

$\mathrm{Na}$ realização do levantamento do Estado do Conhecimento sobre a produção científica realizada, a qual enfocou a categoria História das Instituições Escolares, foram cumpridas as seguintes etapas:

1) levantamento da produção científica dos Programas de Pós-Graduação;

2) leitura do material para identificação da temática selecionada;

3) organização e síntese dos dados em quadros e tabelas;

4) elaboração do banco de dados com os seguintes indicadores: instituição, nome do(a) autor(a), título, ano de obtenção, palavras-chave, nome do(a) orientador(a), área de conhecimento e nível;

5) leitura analítica das informações obtidas e elaboração do texto.

Após o levantamento e elaboração do banco de dados procedeu-seu a análise do material, considerando as pesquisas que privilegiaram o tema "instituições escolares agrícolas". Para que uma análise tenha significado para o pesquisador, é importante que o objeto de estudo esteja inserido numa realidade objetiva concreta.

Assim, explicar a institucionalização dos colégios agrícolas no país e no estado do Paraná somente a partir dos dados coletados poderá levar o pesquisador a cair num reducionismo do seu objeto de estudo. Para não cair nesse reducionismo, a análise empreendida concebeu a constituição da realidade inserida no processo histórico que, por força da luta provocada pelas contradições, efetivou-se num processo dialético.
O embasamento teórico que orienta a análise parte da afirmação de Karl Marx ao compreender o homem como sujeito real, pois vive numa realidade objetiva concreta, material, e tem sua historicidade. Assim, o objeto do conhecimento é a realidade do sujeito, é o espaço material no qual ele está inserido. Além de estar nela inserido, essa realidade é construída pelo próprio homem a partir das condições materiais que lhe são postas pela natureza, pelas suas necessidades e pelas novas relações que vão estabelecendo com o mundo e com os outros homens (Marx, 1987).

Marx e Engels, na Ideologia Alemã, assim explicam:

O modo pelo qual os homens produzem seus meios de vida depende, antes de tudo,da natureza dos meios de vida já encontrados e que tem que reproduzir. Não se deve considerar tal modo de produção de um único ponto de vista, a saber: a reprodução da existência física dos indivíduos. Trata-se, muito mais, de uma determinada forma de atividade dos indivíduos, determinada forma de manifestar sua vida, determinado modo de vida dos mesmos. Tal como os indivíduos manifestam sua vida, assim são eles. O que eles são coincide, portanto, com sua produção, tanto com o que produzem, como o modo como produzem. O que os indivíduos são, portanto, depende das condições materiais de sua produção. (1977, p. 27-8).

E adiante:

A produção de idéias, de representações, da consciência, está, de início, diretamente entrelaçada com a atividade material e com o intercâmbio material dos homens, como a linguagem da vida real. (...). Ou, em outras palavras: não se parte daquilo que os homens dizem, imaginam ou representam, e tampouco dos homens pensados, imaginados e representados para, a partir daí, chegar aos homens em carne e osso; parte-se dos homens realmente ativos e, a partir do seu processo de vida real, expõe também o desenvolvimento dos reflexos ideológicos e dos ecos desse processo de vida. E mesmo as formações nebulosas no cérebro do homem são sublimações necessárias do seu processo de vida material, empiricamente 
constatáveis e ligado a pressupostos materiais. Não é a consciência que determina a vida, mas a vida que determina a consciência. (1977, p. 37).

Ainda na obra "A Ideologia Alemã", Marx destaca as características básicas do conhecimento histórico através da crítica à ideologia alemã. A concepção norteadora dessa obra parte do pressuposto de que a historiografia deve partir dos fundamentos naturais e de uma modificação no curso da história pela ação dos homens.

As premissas de que se parte não se constituem bases arbitrárias, nem dogmas; são antes bases reais de que só é possível abstrair no âmbito da imaginação. As premissas são os indivíduos reais, a sua ação e as suas condições materiais de existência, quer se trate daquelas que eles encontraram já elaboradas, quando do seu aparecimento, quer das que eles próprios criaram. Essas bases são, portanto, verificáveis por vias puramente empíricas.

A análise dialética da história parte, assim, de premissas empíricas, sendo que a primeira premissa é a existência de indivíduos vivos. A segunda premissa é a diferenciação do homem em relação ao animal, é o momento em que ele consegue produzir seu meio de vida. A diferença entre a história do homem e a dos outros animais é que os homens têm em vista um propósito, uma finalidade naquilo que planejam e fazem, enquanto que nos animais a história é feita sem que estes elaborem um projeto próprio de sua história. E a terceira premissa é o modo de produzir, ou seja, o modo como os homens produzem seu meio de vida depende do modo de produzir a sua vida. Marx e Engels, ao se referirem à história, destacam que o primeiro ato histórico é a produção da própria vida material. A história somente pode ser estudada pela conexão material dos homens entre si, mediante a análise da história da produção material da vida humana.

Sob essa perspectiva, a história das instituições escolares parte da realidade concreta e das contradições provocadas pela luta de classes. Assim, este texto sobre a historiografia das instituições escolares agrícolas pretende explicitar os seguintes tópicos:

- discussão entre História, História da Educação e a intensificação dos estudos sobre as instituições escolares;

- compreensão do estudo sobre a história das instituições escolares a partir das relações com as condições sociais nas quais se institucionalizaram;
- análise da produção historiográfica sobre as instituições escolares profisisonalizantes.

\section{História e História da Educação}

As pesquisas educacionais direcionadas para a análise da produção historiográfica têm mostrado a importância do estudo sobre a história das instituições escolares. Mais do que reconstruir sua trajetória, os pesquisadores procuram analisar os elementos que influenciam e que sofrem influências dessas instituições. Nesse aspecto, uma historiografia totalitária focaliza e apreende a instituição escolar na sua complexidade interna e na sua relação externa com diversos agentes. Assim, este estudo tem por objetivo refletir sobre a contribuição da produção historiográfica, privilegiando as pesquisas que abordam a temática do ensino profissionalizante e a criação das instituições escolares que objetivam esse fim. O mapeamento da produção sobre a temática do ensino profissionalizante no $\mathrm{Pa}$ raná pretende realizar um balanço sobre o estado da arte em história da educação brasileira, enfatizando as instituições escolares destinadas à profissionalização da população. Nessa produção são analisadas as pesquisas, dissertações e teses. Num segundo momento, a reflexão privilegiará a análise das fontes documentais levantadas, bem como as fontes iconográficas, documentos oficiais que se encontram em bibliotecas públicas e particulares, acervos de documentos pessoais e imagens. As fontes apontadas se desvelam como um potencial revelador das imbricações existentes entre o estado, trabalho e educação. Assim, busca-se uma pesquisa que colabore no entendimento da história regional a partir da História, entendida na sua totalidade e condicionada conforme o referencial teórico metodológico do materialismo dialético.

Partindo da análise histórica, considera-se que discutir a História não é uma tarefa fácil e, sendo assim, inserir a História da Educação nesse panorama torna-se uma empreitada que exige que o estudo enfoque a sua totalidade. É necessário buscar no passado os elementos necessários para a compreensão do presente como processo, é entendimento que remete a Hobsbawm (1998), quando indica como importante esse movimento de compreensão. Nesse sentido, analisar o passado dos homens e sua produção de vida é fundamental como ferramenta analítica para a concepção 
do presente. Assim, a História deve ser tomada a partir da sua totalidade, condicionada conforme o referencial teórico metodológico do pesquisador.

No âmbito da pesquisa histórica percebe-se a presença e a renovação da concepção teórico-metodológica, superando uma historiografia baseada na descrição de fatos políticos, acentuados pela visão positivista. Nesta ótica as ciências da sociedade, assim como as da natureza, devem limitar-se à observação e à explicação causal dos fenômenos, de forma objetiva, neutra, livre de julgamentos de valor ou ideologias, descartando previamente todas as pré-noções e preconceitos.

Na obra "História e História da Educação" (1998), o professor Dermeval Saviani faz um esboço do panorama da História enquanto problema filosófico e científico, emergido a partir da época moderna. Ressalta questões como a persistência da História como narrativa e "a pouca familiaridade dos historiadores com o trato da teoria, com a reflexão filosófica e epistemológica da ciência" (p. 8), avaliando como esses problemas têm suas consequências para a pesquisa educacional. Porém, destaca o esforço dos investigadores-pesquisadores especializados na História da Educação, a fim de superar as lacunas teóricas.

Essa concepção de história tradicional foi rompida a partir do movimento que se traduziu na "Escola dos Annales", na tentativa de superação da história positivista e na construção de uma história totalizante. A partir dos anos de 1970, a adoção de novos pressupostos estruturalistas oriundos da filosofia, da linguística e da etnologia apontam para a "Nova História". A Nova História, "pretende ser uma história escrita por homens livres ou em busca de liberdade, a serviço dos homens em sociedade" (LE GOFF, 2001, p. 21).

O entendimento de que o discurso historiográfico deixou de ser visto como uma justaposição de fatos, uma descrição dos eventos, e passou a ter um fio condutor com novas propostas metodológicas em campos de investigação múltiplos, ampliando os objetos e estratégias de pesquisas e realizando a reivindicação do individual, do subjetivo, do simbólico como dimensões pertinentes à análise histórica, tornou-se um fato essencial ao historiador. A Nova História faz uma crítica à noção de fato e tempo históricos e propõe uma historiografia problematizadora, e não automática, em que o presente seja compreendido pelo passado e a compreensão deste surja das necessidades do presente.
Desde o surgimento do movimento da "Escola dos Annales" inúmeras discussões decorreram em torno de uma história "aberta" à contribuição de vários campos de conhecimento, como propuseram Bloch e Febvre. A ênfase à recusa dos autores a uma história linear voltou-se para a direção de diferentes dimensões da vida dos homens. Ainda, neste sentido, a utilização de fontes e a sua procura delinearam novas reflexões metodológicas, como, por exemplo, acerca do tempo e de suas múltiplas dimensões.

A principal herdeira da História Nova, a História Cultural, tornou-se um campo fértil e privilegiado academicamente. Entretanto, um olhar mais minucioso demonstra indefinições nas relações entre a Nova História, a História das Mentalidades, a História Cultural, a História Social e seus entrelaçamentos com outras "histórias". Mais problemático ainda é constatar que a História da Educação não é considerada como nenhum deles, a não ser em textos escritos por pesquisadores diretamente nela envolvidos.

A critica presente à "Nova História" é pela grande repartição dos estudos em objetos cada vez menores, ocasionando dificuldades de conseguir uma síntese, em decorrência da profusão de diferentes objetos.

Nessa mesma obra, José Paulo Netto (1998) faz uma análise da concepção de História partindo do conceito elaborado por Marx, a partir de sua produção teórica, o que denomina "teoria marxiana da História". Para isso, apresenta a trajetória da obra de Marx, concluindo por sua atualidade em relação à análise das transformações da sociedade, hoje. $\mathrm{O}$ Marxismo foi a primeira corrente a colocar o problema do condicionamento histórico e social do pensamento e a "desmascarar" as ideologias de classe por detrás do discurso pretensamente neutro e objetivo dos economistas e outros cientistas sociais.

Karl Marx utilizou o método dialético para embasar sua teoria como recurso para contestar e rever as distorções da historiografia positivista. Através do Materialismo Histórico, Marx propõe compreender o funcionamento da sociedade para poder modificá-la. Essa modificação somente poderia ocorrer por meio de uma revolução proletária, onde a burguesia seria retirada do controle dos bens de produção, que passariam a ser controlados pelos trabalhadores.

A primeira contribuição do marxismo relaciona-se à sua abordagem teórico-metodológica consubs- 
tanciada no materialismo histórico. Karl Marx utilizou o método dialético para explicar as mudanças importantes ocorridas na história da humanidade através dos tempos. Ao estudar determinado fato histórico, ele procurava seus elementos contraditórios, buscando encontrar aquele elemento responsável pela sua transformação num novo fato, dando continuidade ao processo histórico. Marx desenvolveu uma concepção materialista da História, afirmando que o modo pelo qual a produção material de uma sociedade é realizada constitui o fator determinante da organização política e das representações intelectuais de uma época.

José Paulo Netto (1998) chama a atenção para uma operação teórica presente nas obras inseridas no interior da Nova história: o cancelamento do século XIX obnubilando grandes matrizes teóricas como Kant, Hegel, Marx, e Nietzsche. Mas, empreender uma síntese do materialismo histórico também apresenta suas dificuldades, já que existem inúmeros desmembramentos dessa teoria. Por isso, José Paulo Netto (1998) fala em "teoria marxiana", sintetizando-a em categorias:

[...] processo objetivo, isso significa que se trata de uma processualidade que porta em si mesma uma especificidade primariamente independente das representações que dela façam os sujeitos; segundo, esse processo é contraditório, já que ele é marcado pela tensão entre os interesses sociais que circunscrevem os diferentes sujeitos em presença; terceiro, é um processo com sujeitos, seus sujeitos reais não se plasmam como personalidades singulares, mas como grupos sociais vinculados por interesses comuns; quarto, projetos que são conduzidos por sujeitos determinados, isto é, tais sujeitos não se constituem aleatoriamente, mas segundo imperativos e possibilidades que se colocam concretamente nos espaços e tempos precisos; quinto, são sujeitos conscientes, ou seja, esses sujeitos não atuam cegamente mas direcionados pelo maior ou menor grau de conhecimento que têm dos limites e possibilidades da sua ação. E seis, é um processo que é marcado pela ação dos sujeitos que têm finalidades, têm intenções, sendo, pois, um processo tencionado por sujeitos com suas próprias teleologias. (NETTO, 1998, p.55).

Cada objetivo do processo histórico, destacado por José Paulo Neto, responde com um aparente paradoxo, pois seus sujeitos atuam com intencionalidades determinadas, mas o processo em si mesmo carece de intencionalidade.
José Paulo Neto deixa claro também a matriz paradigmática da teoria elaborada por Marx e Engels, associando-a a tradição de investigação sobre a verdade aristotélica. A este respeito é conveniente recorrer ao próprio Marx, no "Posfácio da Segunda Edição" de O Capital:

[...] é, sem dúvida, necessário distinguir o método de exposição formalmente, do método de pesquisa. A pesquisa tem de captar detalhadamente a matéria, analisar as suas várias formas de evolução e rastrear sua conexão íntima. Só depois de concluído esse trabalho é que se pode expor adequadamente o movimento real. Caso se consiga isso, e espelhada idealmente agora a vida da matéria, talvez possa parecer eu se esteja tratando de uma construção a priori (MARX, 1983, p.20).

Para o autor Neto, Marx inaugura um modo determinado de ver a realidade, quando enfatiza, na obra A Ideologia Alemã, que "[...] só conhecemos uma ciência, a ciência da história" (1993, p. 61). O seu ponto de partida para a análise da sociedade é o movimento do capital.

Apropriadamente, José Roberto do Amaral Lapa faz uma distinção entre os conceitos de História e Historiografia:

Dessa maneira, o objeto do conhecimento histórico é o que chamamos História para efeito de nossas proposições. É a chamada realidade objetiva do materialismo histórico. Conhecimento histórico é o que resulta do processo limitativo de conhecimento e reconstituição, análise e interpretação daquele objeto, vindo a Historiografia a ser a análise crítica do conhecimento histórico e historiográfico, e do seu processo de produção, reconhecendo, portanto, um conhecimento científico que se perfila aos métodos, técnicas e leis da ciência histórica. (LAPA, 1981, p.19).

Para o autor, o objeto do conhecimento histórico é a História, entretanto ele diferencia e localiza o lugar e o papel da Historiografia, ao afirmar que ela é a análise crítica do conhecimento histórico e historiográfico e do seu processo de produção.

Conhecer as posições elencadas pelos diversos pesquisadores contribui para o entendimento do conhecimento histórico, neste caso particularmente, da História da Educação.

Para Mirian Warde, 
Apesar de um relativo avanço conceptual representado por novas práticas historiográficas e orientações metodológicas, é imperioso reconhecer que as mesmas não estão superando antigos desafios e concepções sociais com os quais paradigmas anteriores há mais tempo se defrontam. (WARDE, 2000, p. 85).

No texto Contribuições para a História da Educação (1990), Warde faz um alerta para os problemas epistemológicos e entende que a História da Educação deve ser considerada como uma especialização da História.

Entretanto, durante a trajetória da História da Educação no Brasil, ela vem marcada em seu itinerário pela relação proximal com a disciplina de Filosofia da Educação. Na sua origem e desenvolvimento, a História da Educação esteve presente nos currículos dos cursos de formação de professores. Esse cenário sofreu alterações a partir dos anos 1960 e início dos 70, com o surgimento dos Programas de Pós-Graduação em Educação no país ${ }^{65}$; dos anos 1980 , com a criação do Grupo de Trabalho "História da Educação", da Associação Nacional de Pós-Graduação e Pesquisa em Educação (ANPEd), e 1984, com a criação do Grupo de Estudos e Pesquisas "História, Sociedade e Educação no Brasil" (HISTEDBR).

A partir dos cursos de pós-graduação e dos grupos de pesquisas, cresceu substantivamente a produção de trabalhos em História da Educação no Brasil. Ao mesmo tempo constituiu-se certa identidade, ainda que multifaceta e plural, do historiador da educação.

O professor luso Justino Pereira de Magalhães (2004) considera que, com a renovação da História da Educação, esta adquiriu uma identidade epistemológica, embora seja marcada por ambiguidades e fragilidades quanto à conceitualização e definição de um campo disciplinar.

A elaboração de uma problemática relativa à história das instituições escolares possibilita a construção de uma história que pouco é abordada e interpretada pelos pesquisadores. É imprescindível destacar que a história de instituições educacionais vem assumindo uma importância fundamental no cenário da pesquisa em educação no Brasil, mesmo diante dos obstáculos encontrados, tais como a precária organização das fontes primárias.

Magalhães (2004) salienta também que, a partir da década de 1960, a historiografia da educação tem

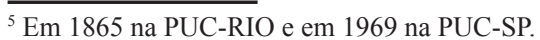

evoluído por meio de um revisionismo crítico e pela construção de uma internalidade que permite compreender e explicar os fenômenos educativos. Alerta, ainda, que essa evolução historiográfica assinala uma superação lenta das correntes histórico-sociológicas.

A Escola dos Annales se desenvolveu conferindo coerência a abordagens complexas e multifacetadas, procurando contrapor-se ao positivismo e à segmentação teórico-metodológica por meio de metodologias articuladas e integrativas.

Já a historiografia "marxista" desenvolveu uma utensilagem teórica e prática com objetivos definidos, nos planos da descrição, compreensão e interpretação/ explicação.

Ao inventariar as principais linhas de renovação da historiografia da educação, Magalhães considera a história das instituições escolares um desafio interdisciplinar, ampliando o matiz investigativo historiográfico: nesse tipo de pesquisa, as análises sociológicas, organizacionais e curriculares compilam-se com o objetivo de uma reconstrução historiográfica de valor. O autor ainda coloca que, a partir dos Annales, passou-se a buscar uma reconstrução do cotidiano individual e institucional, contextualizando-se a instituição pesquisada no cenário político, social, cultural e educacional em que ela se desenvolveu.

A instituição educativa é, assim, apresentada com suas ações pedagógicas e organizacionais no complexo binômio espaço/tempo, em que se inter-relacionam elementos materiais e humanos, um conjunto de categorias conceituais que podem ser percebidas e analisadas dentro da estrutura escolar, tais como o tempo, o calendário escolar, o currículo, os espaços, os professores, os manuais escolares, a interação educativa.

Assim, a investigação "[...] constrói-se entre a materialidade, a representação e a apropriação. As instituições educativas e por conseqüência a sua história constituem a representação discursiva, memorística e antropológica das mais complexas dialécticas educacionais" (MAGALHÃES, 2004, p. 64).

A pesquisa historiográfica dessas instituições tem privilegiado um roteiro de pesquisa com algumas preocupações delimitadas, como a criação e o desenvolvimento dessas instituições, a arquitetura do prédio escolar e sua organização espacial, os docentes, os discentes e o saber pesquisa historiográfica.

Em se tratando das instituições escolares-rurais, o fio condutor é a análise da sua constituição em deter- 
minado espaço e tempo, ou ainda, conforme Saviani (2007, p. 5), "[...] o processo de criação de instituições coincide com o processo de institucionalização de atividades que antes eram exercidas de forma não institucionalizada, assistemática, informal, espontânea".

Tomando como referência o ensino agrícola, no contexto de desenvolvimento social, econômico e político, o interesse pela questão agrária no país só se tornou uma questão relevante a partir das novas demandas produtivas do modelo capitalista, que começava a tomar forma no processo interno de produção. Para tanto, se fazia necessária a formação da mão-de-obra especializada, problema esse que foi solucionado com a criação, em 1859, do Instituto Baiano de Agricultura. Somente nos governos republicanos a questão agrária ressurgiu nas discussões como uma forma de substituir os velhos métodos pelas novas técnicas e pela introdução em larga escala de recursos mecânicos que ampliassem a produtividade e melhorassem a qualidade dos produtos e, consequentemente, o valor econômico da produção. O ponto de partida para essa mudança se deu por meio da organização do ensino agrícola através da promulgação da Lei Orgânica do Ensino Agrícola.

A reconstrução histórica das instituições escolares destinadas ao ensino agrícola no país implica reconhecê-las pelo seu caráter durável, inserindo-as de forma interativa no quadro mais amplo do sistema educativo. A reconstrução do conhecimento do objeto corresponde ao instituído, à institucionalização/representação e à instituição/apropriação, conforme explica Magalhães (2004, p. 138). Ao interpretar o esquema proposto pelo autor, é possível considerar que se entende a escola instalada como o instituído, envolvendo as condições físicas, equipamentos, material didático e sua estrutura organizacional. A institucionalização corresponde ao sentido atribuído ao papel desempenhado pela instituição escolar e, finalmente, a instituição enquanto definidora da identidade dos sujeitos.

Compreender essa tríade ao analisar a história das instituições escolares requer relacioná-las às condições sociais nas quais se institucionalizaram, ou seja, analisar o movimento da história a partir da sua totalidade.

\section{A História das Instituições Escolares}

As pesquisas sobre instituições escolares desenvolveram-se principalmente a partir dos anos
1990, apesar de alguns trabalhos nessa temática terem sido produzidos antes dessa época. Pode-se, porém, identificar três momentos distintos dessa produção: num primeiro momento situado nas décadas de $1950 \mathrm{e}$ 1960, anteriormente aos programas de pós-graduação, a pesquisa e a produção historiográfica da educação brasileira foram desenvolvidas na Seção de Pedagogia da Faculdade de Filosofia, Ciências e Letras da USP; um segundo momento foi marcado pela criação e expansão dos Programas de Pós-Graduação em Educação, nas décadas de 1970 e 1980, contendo duas características a produção desse momento: a escolarização da produção da pesquisa e a reação aos governos militares; o terceiro momento inicia-se nos anos 1990 e caracteriza-se pela consolidação dos cursos de pós-graduação, teoricamente marcados pela crise dos paradigmas (NOSELLA; BUFFA, 2005).

Ainda segundo Paolo Nosella e Ester Buffa, para alguns estudiosos, o presente momento da produção historiográfica sobre a história das instituições escolares caracteriza-se por uma fragmentação epistemológica e temática que dificulta a compreensão da totalidade do fenômeno educacional. Muitos desses estudiosos veem, nessa crise paradigmática, um largo movimento antimarxista e o abandono da perspectiva histórica. E nessa perspectiva, dentre os vários temas pesquisados, destacam-se as instituições escolares. (NOSELLA; BUFFA, 2005).

Essas normas e práticas complexas que variam no espaço e no tempo, e que podem até coexistir mantendo suas diferenças, aninham-se na instituição escolar e é possível evidenciá-las a partir dos seguintes tópicos que funcionam como categorias de análise: o contexto histórico e as circunstâncias específicas da criação e da instalação da escola; seu processo evolutivo: origens, apogeu e situação atual; a vida da escola; o edifício escolar: organização do espaço, estilo, acabamento, implantação, reformas e eventuais descaracterizações; os alunos: origem social, destino profissional e suas organizações; os professores e administradores: origem, formação, atuação e organização; os saberes: currículo, disciplinas, livros didáticos, métodos e instrumentos de ensino; as normas disciplinares: regimentos, organização do poder, burocracia, prêmios e castigos; os eventos, festas, exposições, desfiles e outros. (NOSELLA; BUFFA, 2005).

Os autores concluem afirmando que, no tocante às pesquisas em história da educação sobre institui- 
ções escolares, não se pode admitir que a descrição pormenorizada de uma dada instituição escolar deixe de levar o leitor à compreensão da totalidade histórica (NOSELLA; BUFFA, 2005).

O estudo sobre a história das instituições escolares também pode ser analisado pela ótica do estudo da cultura escolar. Julia (1995) define cultura escolar como

Um conjunto de normas que definem conhecimentos a ensinar e condutas a inculcar, e um conjunto de práticas que permitem a transmissão desses conhecimentos e a incorporação desses comportamentos; normas e práticas coordenadas a finalidades que podem variar segundo épocas (finalidades religiosas, sociopolíticas ou simplesmente de socialização). Normas e práticas não podem ser analisadas sem se levar em conta o corpo profissional dos agentes que são chamados a obedecer a essas ordens e, portanto, a utilizar dispositivos pedagógicos encarregados de facilitar sua aplicação, a saber, os professores primários e os demais professores. Mas, para além dos limites, pode-se buscar identificar, em um sentido mais amplo, modos de pensar e de agir largamente difundidos no interior de nossas sociedades, modos que não concebem a aquisição de conhecimentos e de habilidades senão por intermédio de processos formais de escolarização [...]. Enfim, por cultura escolar é conveniente compreender também, quando isso é possível, as culturas infantis (no sentido antropológico do termo), que se desenvolvem nos pátios de recreio e o afastamento que apresentam em relação às culturas familiares. (JULIA, 2001, p. 10-11).

Entretanto, neste estudo, elegeu-se como referencial teórico metodológico o materialismo dialético para compreender a institucionalização dos colégios agrícolas no país. Para Buffa (2002) pesquisar uma instituição escolar é uma forma de estudar a filosofia e história da educação brasileira, porque essas instituições estão impregnadas de valores e políticas educacionais que deixam marcas na escola.

Embora não seja fácil fazer uma síntese dos apontamentos e comentários enriquecedores vividos durante o percurso, procurou-se destacar, brevemente, pontos relevantes e merecedores de destaque sobre a pesquisa que aborda a temática "instituições escolares".

\section{Os Estudos sobre as Instituições Escolares Agricolas}

Diante dos apontamentos acerca da história das instituições escolares, a análise deteve-se no estudo das instituições que oferecem ensino agrícola. Entretanto, cabe destacar que a análise não está finalizada, mas pretende contribuir com um breve balanço da produção historiográfica brasileira. Cabe, ainda, salientar que mediante a necessidade de delimitação do espaço das produções, não foram consultados as pesquisas e estudos elaborados pelos grupos de pesquisa em História da Educação, como o Grupo de Estudos e Pesquisas História, Sociedade e Educação no Brasil - HISTEDBR; o Grupo de Trabalho de História da Educação da Associação Nacional de Pós-Graduação em Educação - ANPEd, e as produções decorrentes dos Seminários realizados pela Sociedade Brasileira de História da Educação que muito têm contribuído para a discussão dessa temática.

Inicialmente, as produções selecionadas foram organizadas por região, conforme quadro:

Tabela 1 - Tabela de distribuição da produção científica por Região Brasileira

\begin{tabular}{|c|c|}
\hline REGIÃO & TOTAL \\
\hline Centro-Oeste & 03 \\
\hline Norte & -- \\
\hline Nordeste & 04 \\
\hline Sudeste & 04 \\
\hline Sul & 03 \\
\hline TOTAL & 14 \\
\hline
\end{tabular}

Constatou-se que a produção dos Programas de Pós-Graduação em Educação que abordam a história das instituições escolares agrícolas tem se concentrado nas regiões Nordeste e Sudeste, e que as regiões Sul e Centro-Oeste apresentam o mesmo número de pesquisas. Quanto à região Norte, dentre os Programas pesquisados não se encontrou nenhuma pesquisa. A predominância de pesquisas nas regiões Nordeste e Sudeste - principalmente na última - deve-se à localização geográfica das instituições que oferecem Programas de Pós-Graduação que recebem pesquisadores de diferentes regiões do país. 
Procurou-se ainda verificar a origem das pesquisas, examinando sua distribuição nos diversos programas de pós-graduação, destacando a instituição e o estado, conforme consta na tabela 2.

Tabela 2 - Tabela de distribuição das produções por Estado e instituição

\begin{tabular}{|c|c|c|}
\hline ESTADO & INSTITUIÇÃO & TOTAL \\
\hline CE & Universidade Federal do Ceará & 1 \\
\hline DF & Universidade de Brasília & 1 \\
\hline GO & Universidade Federal de Goiás & 1 \\
\hline MG & $\begin{array}{l}\text { Universidade Federal de Lavras } \\
\text { Universidade Federal de } \\
\text { Uberlândia }\end{array}$ & $\begin{array}{l}1 \\
1\end{array}$ \\
\hline MT & $\begin{array}{l}\text { Universidade Federal do } \\
\text { Mato Grosso }\end{array}$ & 1 \\
\hline PE & $\begin{array}{l}\text { Universidade Federal de } \\
\text { Pernambuco }\end{array}$ & 1 \\
\hline PI & Universidade Federal do Piauí & 1 \\
\hline RS & $\begin{array}{l}\text { Universidade Federal do } \\
\text { Rio Grande }\end{array}$ & 1 \\
\hline SC & $\begin{array}{l}\text { Universidade Federal de } \\
\text { Santa Catarina }\end{array}$ & 1 \\
\hline SE & Universidade Federal de Sergipe & 1 \\
\hline SP & $\begin{array}{l}\text { Universidade Federal de } \\
\text { São Carlos } \\
\text { Universidade Metodista de } \\
\text { Piracicaba } \\
\text { Universidade de São Paulo }\end{array}$ & $\begin{array}{l}1 \\
1 \\
1\end{array}$ \\
\hline
\end{tabular}

As temáticas levantadas abordam a história das instituições escolares delimitando como período histórico a metade do século XIX até o século XX. A institucionalização das instituições escolares ampliou-se fortemente nesse período histórico. O professor Sérgio Castanho, no texto "Institucionalização das Instituições Escolares", justifica que a "institucionalização das instituições escolares realmente foi um fenômeno que caracterizou fortemente a quadra final do século XIX e a inicial do século XX" (2007, p. 54).

Dentre as pesquisas selecionadas, conforme a temática delimitada, estão centradas na análise da história das instituições escolares agrícolas:

Ana Pereira Negry Muta (2002) discute os desafios da Escola Família Agrícola de Porto Nacional. Ainda enfrenta um árduo processo de legalização e reconhecimento que esbarra, sobretudo, na visão tra-

\footnotetext{
${ }^{6}$ O referido texto faz parte da coletânea Instituições Escolares no Brasil (2007).
}

dicionalista do sistema de educação e de seus técnicos, quanto ao tipo e função da escola rural.

Abimael Antunes Marques (2005) faz uma análise sobre o Aprendizado Agrícola "Gustavo Dutra" no conjunto do sistema educacional de Mato Grosso, entre 1943 e 1947, onde destacou sua especificidade enquanto escola federal, de cunho rural, enfatizando sua colaboração enquanto diferencial na formação do trabalhador mato-grossense.

João Batista Pereira de Queiroz (2004), em sua tese de doutoramento em Sociologia, analisa o surgimento e o desenvolvimento das Escolas Famílias Agrícolas de Ensino Médio e Educação Profissional, que surgiram no Brasil a partir das experiências francesas e italianas.

Milton Ramon Pires de Oliveira (2000), em sua tese de doutoramento, enfoca o processo de constituição dos patronatos agrícolas enquanto instrumentos de assistência à infância e adolescência pobres durante a $1^{\text {a }}$ República, concorrendo para a conformação da força de trabalho segundo os princípios demandados pelas relações sociais de produção em consolidação na sociedade brasileira.

Adlene Silva Arantes (2005) procura compreender a educação, a instrução e os possíveis destinos pensados para os meninos negros, brancos e índios na Colônia Orfanológica Isabel, instituição criada pelos Missionários Capuchinhos, com o objetivo de receber crianças órfãs e ingênuas. Para os alunos disciplinados, buscava-se garantir o direito de concluir uma educação voltada para a agricultura e uma possível colocação no mercado de trabalho; já para os incorrigíveis, a expulsão era a medida tomada pela instituição.

Julinete Vieira Castelo Branco (2006) reconstrói as histórias e memórias do Colégio Agrícola de Teresina, a partir da análise da sua trajetória desde o momento de criação da Escola Agrotécnica de Teresina, em 1954, até a sua incorporação à Universidade Federal do Piauí, em 1976.

Marco Arlindo Amorim Melo Nery (2006) busca compreender o processo de implementação, os objetivos e as práticas educativas do Patronato Agrícola de Sergipe, criado pelo Presidente do Estado, Maurício Graccho Cardoso, no ano de 1924.

Thiago de Oliveira Andrade (2006), em sua dissertação de mestrado, investiga a criação da Escola Superior de Agricultura de Lavras (ESAL), desde 
a fundação em 1908, quando o Reverendo Samuel Rhea Gammon decidiu criar uma escola que ensinasse agricultura aos jovens da região, segundo os valores do ideário protestante.

Ademir Valdir dos Santos (1999) analisa a criação de escolas comunitárias rurais de ensino primário, por imigrantes alemães e seus descendentes, na região de Rio Novo, no município de Corupá, estado de Santa Catarina.

Aluísio José Alves (1999) estuda a gênese do ensino agrotécnico no Brasil e a discussão dos motivos históricos e políticos que levaram à criação das Escolas Agrotécnicas Federais no Triângulo Mineiro.

Marcus Alexandre Pires (2005) busca identificar as condições de oferecimento de regime de internato nas escolas técnicas do setor agropecuário do Centro Estadual de Educação Tecnológica "Paula Souza".

Marly Terezinha Germano Perecin (2002), em sua tese de doutoramento, analisa os projetos de ensino técnico concebidos na última década do século XIX: o de Luiz Vicente de Souza Queiroz, o do engenheiro agrônomo Léon Alphonse Morimont e o oficial, baseado no Decreto ${ }^{\circ} 683$, de 29/12/1899, que regulamentava a Lei n ${ }^{\circ} 678$, de 13/09/1899. As Constituições de 1891 (federal e estadual) favoreceram iniciativas na área do ensino técnico, permitindo a realização das primeiras experiências com a Educação Superior na Escola Politécnica, e Secundária, na Escola Agrícola Prática "Luiz de Queiroz", na cidade de Piracicaba.

Paulo Cesar Gastaldo Claro (2004) investiga o processo de constituição e desenvolvimento da Escola Agrícola Florestal e Ambiental (E.M.A.F.A.) do município de Ilópolis - RS. O estudo examina o processo de emergência e desenvolvimento da Escola Agrícola Florestal e Ambiental, procurando identificar em que medida a instituição, efetivamente, delineia suas ações educativas através da Educação Ambiental.

Cláudio Adalberto Koller (2003) procura reconstruir historicamente o modelo político pedagógico da Escola Agrotécnica Federal de Rio do Sul - EAFRS, buscando os principais fatores que influenciaram na definição do modelo político pedagógico, sua organização didática e funcional, bem como identificar o modelo tecnológico de produção agropecuária adotado e a sua influência, ou não, no índice de retorno dos alunos formados às propriedades agrícolas de origem.

O mapeamento das pesquisas também revelou que dentre as instituições pesquisadas a temática so- bre a análise das instituições escolares tem sido foco de outras áreas das Ciências, como mostra o quadro a seguir.

Tabela 3 - Tabela de distribuição dos Programas de PósGraduação

\begin{tabular}{|l|c|}
\hline PROGRAMA & TOTAL \\
\hline Educação & 09 \\
\hline Sociologia & 01 \\
\hline Historia & 01 \\
\hline História Social & 01 \\
\hline Educação Ambiental & 01 \\
\hline Agroecossistemas & 01 \\
\hline TOTAL & 14 \\
\hline
\end{tabular}

O levantamento apontou a necessidade de ampliar as pesquisas na área da história da educação, especificamente sobre a história das instituições escolares. Entretanto, como afirmado anteriormente, esse balanço ainda é preliminar e carece de aprofundamentos acerca da periodização e do referencial teórico-metodológico.

Fazer uma pesquisa histórica requer muito mais do que interesse e familiaridade com o tema. É necessário fazer história, e o fazer histórico depende do historiador que atua nessa realidade, seja o passado ou o presente, conforme o seu referencial teórico-metodológico. Como forma de apreender essa realidade o historiador recorre às fontes que se reconstroem através do pensamento.

Em síntese, os temas abordados no texto expressam um entendimento de realizar uma unidade com as temáticas: História, História da Educação e Historiografia. Assim, nesta abordagem, a reconstrução história das instituições escolares agrícolas no país se constitui num esforço de reconstruir o projeto institucional, considerando os períodos históricos que lhe deram origem e caracterizando a sua institucionalização.

Portanto, o projeto de doutoramento, ao analisar as instituições escolares, particularmente, as que se dedicaram ao ensino agrícola no Brasil, pretende reconstruir um pedaço da história da educação, procurando identificar o projeto estatal para a sociedade. 


\section{REFERÊNCIAS}

ALVES, Aluísio José. Escolas agrotécnicas federais no triângulo mineiro: o dogmatismo político-pedagógico versus a formação humana e técnica. 1999. Dissertação (Mestrado em Educação). Universidade Federal de Uberlândia.

ANDRADE, Thiago de Oliveira. Memória e história institucional: o processo de constituição da Escola Superior de Agricultura de Lavras - ESAL - (1892-1938). 2006. Dissertação (Mestrado em Administração). Universidade Federal de Lavras.

ARANTES, Adlene Silva. O papel da Colônia Orfanológica Isabel da educação e na definição dos destinos de meninos negros, brancos e índios na província de Pernambuco (1874-1889). 2005. Dissertação (Mestrado em Educação). Universidade Federal de Pernambuco.

BRANCO, Julinete Vieira Castelo. Histórias e memórias do Colégio Agrícola de Teresina (1954 A 1976): formando líderes para a construção do novo e para a implacável destruição do arcaico. 2006. Dissertação (Mestrado em História). Fundação Universidade Federal do Piauí.

BUFFA, Ester. História e filosofia das instituições escolares. In: ARAÚJO, José Carlos; GATTI Junior, Décio, (Orgs.). Novos temas em história da educação brasileira. Campinas,SP: Autores Associados; Uberlândia, MG: Edufu, 2002.

CLARO, Paulo Cesar Gastaldo. A pronúncia do mundo através da palavra: um estudo sobre o processo de constituição e desenvolvimento da Escola Agrícola Florestal e Ambiental de Ilópolis/RS. 2004. Dissertação (Mestrado em Educação Ambiental). Fundação Universidade Federal do Rio Grande.

JULIA, Dominique. A cultura escolar como objeto histórico. Revista Brasileira de História da Educação, n.1. jan/ jun.2001, p 9-43.

KOLLER, Cláudio Adalberto. A perspectiva histórica da criação da Escola

Agrotécnica de Rio do Sul e sua relação como o modelo agrícola convencional. 2003. Dissertação (Mestrado em Agroecossistemas). Universidade Federal de Santa Catarina.

LAPA, José Roberto do Amaral. Historiografia brasileira contemporânea. 2. ed. Petrópolis/RJ: Vozes, 1981.

LE GOFF, Jacques. A história nova. Tradução de Eduardo Brandão. São Paulo: Martins Fontes, 2001.

LOMBARDI, Jose Claudinei; NASCIMENTO, Maria Isabel Moura. Fontes, história e historiografia da educação. Campinas: Autores Associados, 2004.

MAGALHÃES, Justino Pereira de. Tecendo nexos: história das instituições educativas. Bragança Paulista/SP: Editora Universitária São Francisco, 2004.
MARQUES, Abimael Antunes. Aprendizado agrícola "Gustavo Dutra": seu papel e importância no contexto agrícola de Mato Grosso (1943-1947). Dissertação (Mestrado em Educação). Universidade Federal de Mato Grosso.

MARX, Karl; ENGELS, Friedrich. A ideologia alemã (I Feuerbach). Tradução de José Carlos Bruni e Marco Aurélio Nogueira. 9. ed. São Paulo, Hucitec, 1993.

MUTA, Ana Pereira Negry. Agricultor técnico x técnico agrícola: os desafios da educação rural na Escola Família Agrícola de Porto Nacional, 2002. Dissertação (Mestrado em Educação) - Universidade Federal de Goiás.

NASCIMENTO, Maria Isabel Moura; SANDANO, Wilson; LOMBARDI, José Claudinei; SAVIANI, Dermeval. Instituições escolares no Brasil. Campinas: Autores Associados, 2007.

NERY, Marco Arlindo Amorim Melo. A regeneração da infância pobre sergipana no início do século $\mathrm{XX}$ : o patronato agrícola de Sergipe e suas práticas educativas. 2006. Dissertação (Mestrado em Educação). Fundação Universidade Federal de Sergipe.

NETTO, João Paulo. Relendo a teoria marxista da história. In: SAVIANI, Demerval; LOMBARDI, José Claudinei; SANFELICE, Jose Luís. História e história da educação: o debate teórico-metodológico atual. Campinas: Autores Associados, 1998.

OLIVEIRA, Milton Ramon Pires de. Formar cidadãos úteis: os patronatos agrícolas e a infância pobre na primeira república. 2000. Tese (Doutorado em Educação). Universidade Federal do Ceará.

PERECIN, Marly Terezinha Germano. Os passos do saber: a escola agrícola prática "Luiz de Queiroz" (o esforço para implantar o ensino técnico de segundo grau na agricultura, 1891-1911). 2002. Tese (Doutorado em História Social). Universidade de São Paulo.

PIRES, Marcus Alexandre. A questão do internato nas escolas técnicas de agricultura e pecuária em São Paulo: o caso do Centro Estadual de Educação Tecnológica 'Paula Souza' - CEETEPS. 2005. Dissertação (Mestrado em Educação). Universidade Metodista de Piracicaba.

QUEIROZ, João Batista Pereira de. Construção das escolas famílias agrícolas no Brasil. 2004. Tese (doutorado em Sociologia). Universidade de Brasília.

SANFELICE, Jose Luís. Perspectivas Atuais da História da Educação. IN: LOMBARDI, José Claudinei et al. Educação em Debate, Campinas/SP: Autores Associados, 2006.

SANTOS, Ademir Valdir dos. Educação e imigração: a escola alemã do Rio Novo. 1999. Dissertação (Mestrado em Educação). Universidade Federal de São Carlos. 
SAVIANI, Demerval; LOMBARDI, José Claudinei; SANFELICE, Jose Luís. História e história da educação: o debate teórico-metodológico atual. Campinas: Autores Associados, 1998.

WARDE, Mirian Jorge; CARVALHO, Marta Maria Chagas de. Política e cultura na produção da história da educação no Brasil. Revista Contemporaneidade e Educação, Ano 5, n. 7, 1. Sem. 2000. 